\title{
AC 2012-5046: DEFINING THE CORE BODY OF KNOWLEDGE (COR- BOK) FOR A GRADUATE PROGRAM IN SYSTEMS ENGINEERING: A WORK IN PROGRESS
}

\author{
Dr. Alice F. Squires, Stevens Institute of Technology
}

Alice Squires is Manager of Systems Engineering at Aurora Flight Sciences and an adjunct systems engineering faculty for the School of Systems and Enterprises at Stevens Institute of Technology. She is one of many authors on the Systems Engineering Body of Knowledge (http://www.sebokwiki.org/) and the Graduate Curriculum for Systems Engineering (http://bkcase.org/grcse-05). She was previously a Senior Researcher for the Systems Engineering University Affiliated Research Center (SE UARC) and Online Technical Director for the School of Systems and Enterprises. She has served as a Senior Systems Engineer consultant to Lockheed Martin, IBM, and EDO Ceramics, for Advanced Systems Supportability Engineering Technology and Tools (ASSETT), Inc. Squires also previously served as a Senior Engineering Manager for General Dynamics (GD) and Lockheed Martin (LM), and as a technical lead for IBM. She is an INCOSE-certified CSEP and CSEP-Acq, and she has a Ph.D. in dystems engineering, a M.B.A. and a B.S.E.E. and began her professional career as an analyst for Delex Systems, Inc. Squires is a lifetime member of Beta Gamma Sigma (business), Tau Beta Pi (national engineering), and Eta Kappa $\mathrm{Nu}$ (national electrical engineering) honorary societies and is a member of ASEE, IEEE, NDIA, and INCOSE and Past Chair of the ASEE Systems Engineering Division. Squires received the Stevens Institute of Technology Provost's Online Teaching Excellence Award in 2007; the General Dynamics Technical Achievement in Safety Award in 2002; the Lockheed Martin Outstanding Team Award in 1998; and multiple technical awards from IBM from 1986 to 1993. Her research interests include engineering education, distance education, workforce competency development, and systems thinking.

\section{Dr. Timothy L.J. Ferris, University of South Australia}

Tim Ferris holds B.E. (hons.), Adelaide, BTh, Flinders, BLittHons, Deakin, GradCertEd, QUT, Ph.D., South Australia. He has worked at the University of South Australia for 21 years and is responsible for the teaching activities of the Defence and Systems Institute. He is the Associate Director Academic Research in INCOSE and is the lead author of the Graduate Reference Curriculum for Systems Engineering, GRCSE. His research interests are in the nature of systems engineering, research methods for engineering, cross-cultural issues in engineering practice, and engineering education.

\section{Dr. Joseph J. Ekstrom, Brigham Young University}

Joseph Ekstrom spent 30 years in systems/software development as an engineer and manager. He is currently the Program Chair of the Information Technology program at Brigham Young University. His research interests include network and systems management, distributed computing, system modeling and architecture, system development, cybersecurity, and curriculum development.

\section{Ms. Mary D. VanLeer, Perceptive-Systems}

Mary. VanLeer has more 30 years experience in defining, designing, and supporting IT solutions for high-end data center environments. She has held the positions of Director, Serviceability, Software Engineering, at Sun Microsystems, Director of Engineering Operations at International Game Technology, and Director of Information Technology at the Arkansas Lottery Commission. In those positions, VanLeer introduced new verification methods to test the robustness of the products' system recovery capabilities and led numerous initiatives in the quality efforts for diagnosability, serviceability, and fault management, led an initiative to understand and build the engineering capabilities focusing on systems engineering, and built the internal IT infrastructure for Arkansas's new state lottery. As a member of the International Council on Systems Engineering, VanLeer advocates an agile systems engineering set of disciplines without sacrificing the innovation style of today's engineers.

\section{Mr. Garry Roedler, Lockheed Martin}

Garry Roedler's systems engineering career at LM spans the full system life cycle and includes technical leadership roles in both programs and systems engineering business functions. As a LM Fellow 
and the corporate Engineering Outreach Program Manager, Roedler is responsible for executing an external outreach strategy for LM leadership, influence, and leverage of technical industry associations. Prior roles include: Senior SE Program Manager, managing corporate councils for SE, Test \& Evaluation, and Specialty Engineering focused on engineering practices, training, and improvement; Process Manager in IS\&GS, responsible for strategic planning of technology needs, process technology development/infusion, and process definition/improvement; this included achievement/sustainment of Level $5 \mathrm{SE}$ CMM/CMMI objectives; Technical leadership roles on programs/proposals, Technical Lead for system installation/demonstration/deployment, Customer Liaison, and System Analysis Manager; and mathematics instructor, secondary/college level. Roedler holds degrees in mathematics education and mechanical engineering from Temple University and the Expert Systems Engineering Professional (ESEP) certification from INCOSE. Roedler has numerous publications and presentations, and is the recipient of many awards, including the INCOSE Founders Award, Best SE Journal Article, and IEEE Golden Core. His leadership roles across many technical organizations include editor of ISO/IEC/IEEE 15288, Systems Life Cycle Processes, and several other standards. 


\title{
Defining the Core Body of Knowledge (CorBoK) for a Graduate Program in Systems Engineering: A Work in Progress
}

\begin{abstract}
The Graduate Reference Curriculum on Systems Engineering (GRCSE $E^{\mathrm{TM})}$ version $0.5^{1}$ provides recommendations for the development of graduate level systems engineering curricula. These guidelines address student entrance expectations, a core body of knowledge (CorBoK) and an accompanying set of outcomes that the student is expected to master by graduation, and a sample set of objectives that the student should achieve three to five years after graduation. GRCSE also includes guidelines for implementing the GRCSE recommendations and assessing developed curriculum. This paper is focused on the process that has been used to date to develop the CorBoK recommendations presented in GRCSE.
\end{abstract}

\section{Introduction}

The Body of Knowledge and Curriculum to Advance Systems Engineering (BKCASETM) project is developing two major products for the systems engineering community: a Guide to the Systems Engineering Body of Knowledge (SEBoK) ${ }^{2}$ [see sebokwiki.org] and a Graduate Reference Curriculum for Systems Engineering (GRCSE $\left.{ }^{\mathrm{TM}}\right)^{1}$. GRCSE is being developed to assist in improving existing or developing new graduate programs in systems engineering. The goal of GRCSE is to provide a curriculum framework to institutions for developing and communicating their system engineering graduate program content, leading to a more common understanding of the content that is addressed within the programs and potentially to more consistency across the programs. The authors of GRCSE have recognized that the specific context of each program requires flexibility in the design of the curriculum guidance to enable expression of distinctiveness of universities and programs with respect to the industry sectors and diverse range of work sought from graduates. For these reasons the framework is designed so that institutions can preserve their unique specialties and university-specific requirements.

One of the many challenges in developing GRCSE has been identifying a feasible approach for defining the core body of systems engineering knowledge that every graduate student should be exposed to prior to graduation. GRCSE defines this core body of knowledge (CorBoK) as the set of core topics recommended for inclusion in every professional Masters program; with the intent that mastery of the content of these core topics is required of all graduates. The CorBoK is comprised of two parts: 1) the truly common part: the core foundation to be learned by everyone who goes through the program, and 2) a core concentration that favors one of several emphases. An institution can choose to implement one or more of the concentration areas within their systems engineering program. The idea is that a student would select an available concentration area and learn the corresponding extension of core knowledge in that area, in addition to the knowledge in the core foundation, as part of the CorBoK of the program. GRCSE intentionally limits the CorBoK to no more than $50 \%$ of the total knowledge conveyed in a graduate systems engineering program in order to encourage and enable wide variation across institutions to enable the creation of programs that address a wide range of emphases in systems engineering and the domains in which it is applied. 
This paper describes the approach used to define the CorBoK in the version 0.5 draft of GRCSE released in December 2011; and addresses the challenges faced and lessons learned based on the approach used. The paper then describes future considerations and plans for defining the CorBoK for the version 1.0 release of the GRCSE, which is scheduled for public release in December 2012.

Please note: The scope of this work is only for systems engineering graduate programs due to 1) this effort is a follow-on to the graduate reference curriculum that was developed for software ${ }^{3}$, and 2) the majority of systems engineering programs that have evolved over the past decade are at the graduate level ${ }^{4}$, and 3) this work is focused on professional graduate programs in systems engineering. The initial goal of this work is to have a near-term impact on the more proliferate graduate level systems engineering programs. Thus, while this paper cannot address the core material that should or might be in an undergraduate program in systems engineering, the work does provide insight into what is important in the discipline and can serve as a guide to undergraduate curriculum developers

\section{Background}

GRCSE is built on an holistic interpretation of curriculum as concerning the total context in which education is provided, and as such the recommendations address five primary areas of a systems engineering program: ${ }^{5}$

1) student entrance expectations;

2) a curriculum architecture comprised of:

a. preparatory material,

b. a core body of systems engineering knowledge (the CorBoK),

c. domain or program-specific knowledge, and

d. a capstone experience;

3) outcomes every graduate should achieve;

4) objectives every graduate should achieve three to five years after graduation;

5) an assessment methodology.

GRCSE is intended to inform the development of graduate programs in systems engineering and to support the assessment of these programs. Stakeholders include internal stakeholders such as faculty, students, and school administration and external stakeholders such as employers, professional societies, and chartering or certifying bodies.

The CorBoK is defined as one of the four components of the GRCSE curriculum architecture. ${ }^{1}$ This architecture, as shown in Figure 1, has the baseline represented by a solid black line near the bottom, to depict the idea that the entrance expectations have been met by the student. If these entrance expectations have not been met, the student will normally complete required preparatory material before either being admitted to the program, or continuing in the program. Once the student has met the baseline requirements, the student can proceed to take courses that cover a variety of topics that can cover any combination of foundation, concentration, program or domain-specific knowledge as determined by the institution. Normally the capstone is an "allencompassing" experience that leverages the knowledge previously learned throughout the 
program and takes place as one of the final courses or experiences in the systems engineering program.

\section{The System Concept}

Before planning the approach for defining the CorBoK, the team first had to agree on the CorBoK system concept - namely the size (\% of curriculum) and level of topics to be covered. The initial concept was to limit the CorBoK to no more than $50 \%$ of the curriculum allowing flexibility for each institution, and to address one set of core topics. However, the SE discipline is diverse and has a range of specializations, so the team quickly realized that in order to meet the $50 \%$ requirement, the CorBoK would require two levels of topics. First, the CorBoK needed to cover the topics that all who call themselves systems engineers should master. Second, the CorBoK should support a set of concentrations driven by the needs and roles of the students and their employers. The concentration topics would build on the foundation by either adding new topics or revisiting foundation topics in more depth. The two concentrations selected in the initial step of the process were: systems engineering management (SEM) and systems design and development (SDD). The inclusion of concentrations in the CorBoK allows universities to choose focus areas, which are consistent with their specific program purpose and local requirements. In GRCSE version 0.5 two concentration areas have been developed but the authors believe and expect that several more concentration areas will be determined later in the life of GRCSE.

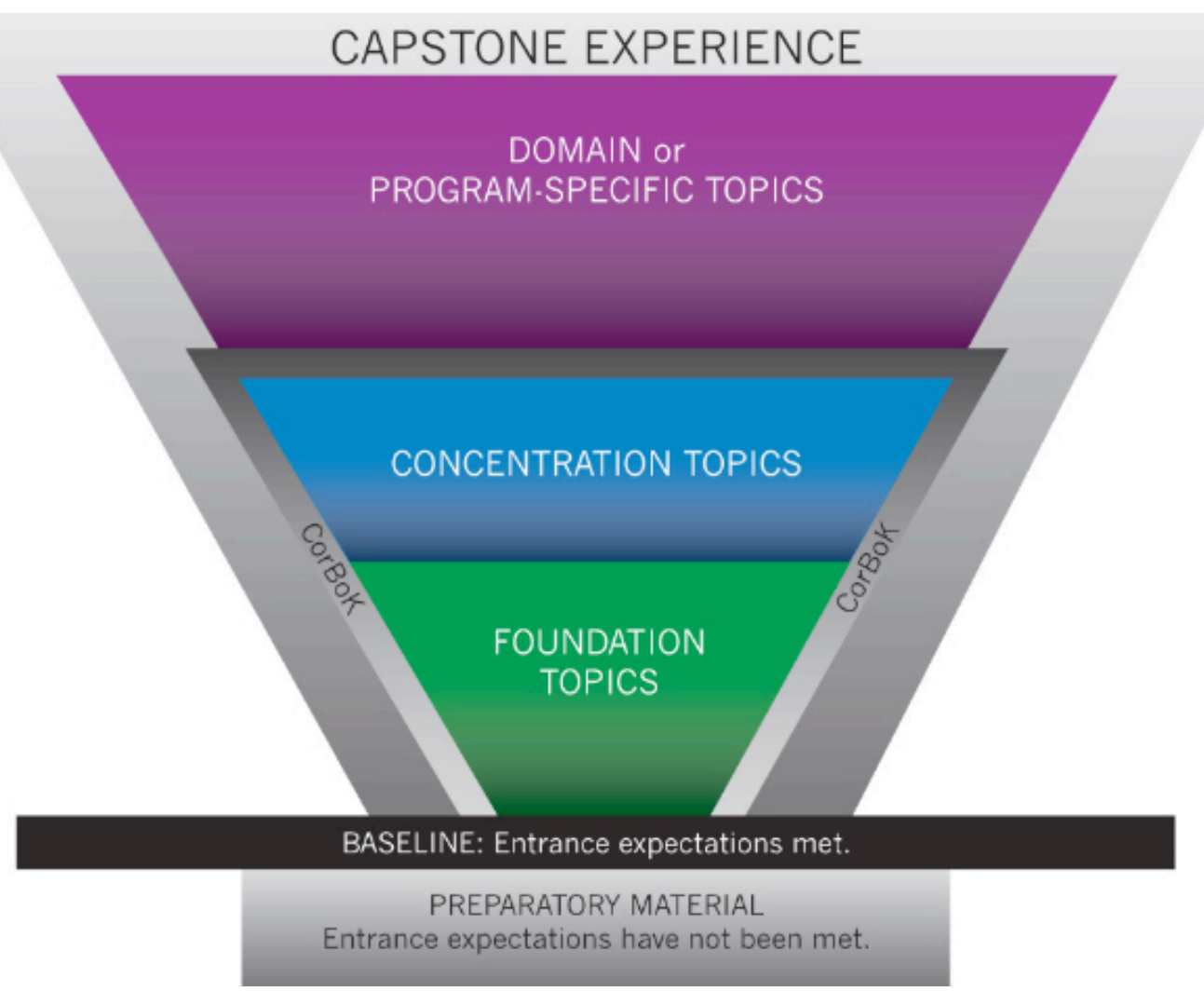

Figure 1. GRCSE Curriculum Architecture ${ }^{1}$ (p. 31) 


\section{The Approach}

Given the system concept, the intention of the GRCSE CorBoK is to identify both the set of foundation and concentration topics, and the Bloom's levels (as defined by Bloom's taxonomy in the cognitive domain - see Appendix A for a brief description) of knowledge required in each topic, that a student should master prior to graduation with a master's degree in SE. In addition, the CorBoK team wanted to provide guidance to the faculty as to the relative number of studentinstructor contact hours required to cover each topic sufficiently to achieve the Bloom's levels specified. To achieve this, the team first developed the following guidelines:

1) The topics for the foundation and concentration areas were constrained, initially (up to the current version) to the topics covered in the SEBoK. ${ }^{2}$ The team did not come to this decision lightly; however, the reasoning was that the SEBoK represented the guide to the SE discipline knowledge and if the topic was not covered in the SEBoK, it was either an oversight (and the GRCSE team would provide this feedback to the SEBoK team), or outside of the core knowledge of SE. Also, additional topics could be included as part of the program or domain-specific portion of the systems engineering curriculum as applicable and feasible, at the judgement of university program leaders. Thus, the overall SE program was not constrained.

2) The structure of the CorBoK would similarly follow the structure of the SEBoK. That is, the CorBoK topics would map directly to SEBoK topics - and not address either higher level SEBoK knowledge areas (KAs) or lower level SEBoK subtopics (see Figure 2 for an example of this). This again required consensus building in the team as the life cycle stages and processes had been aggregated at a high level in the SEBoK and some team members wanted to expand to a more detailed level (e.g. translating stakeholder requirements, or developing verification tests, etc.). Also, the team determined that only the 110 topics in Parts 2 through 6 (see Appendix B) were applicable, and would be included.

Once the topics and structure were identified, the next step in developing the CorBoK was to define the minimum Bloom's level that all SE master's degree students should achieve by graduation in both the foundation and the concentrations (first three steps below). While this part of the approach is easy to describe, the implementation was quite challenging. Once the Bloom's levels were defined, guidelines for the amount of relative time needed for teaching each topic could also be provided. These fours steps are summarized below; additional detail is provided in the following sections:

1) Gathering input from BKCASE authors representing industry, government, and academia around the world.

2) Using the input as guidance, identified those topics that belong in the foundation and the Bloom's levels to be achieved by graduation.

3) Using the input as guidance, identified those topics that belong in each concentration and the Bloom's levels to be achieved by graduation.

4) Providing guidelines for relative level of touch point time required in each area by distributing $100 \%$ first across the parts, and then across the knowledge areas. 


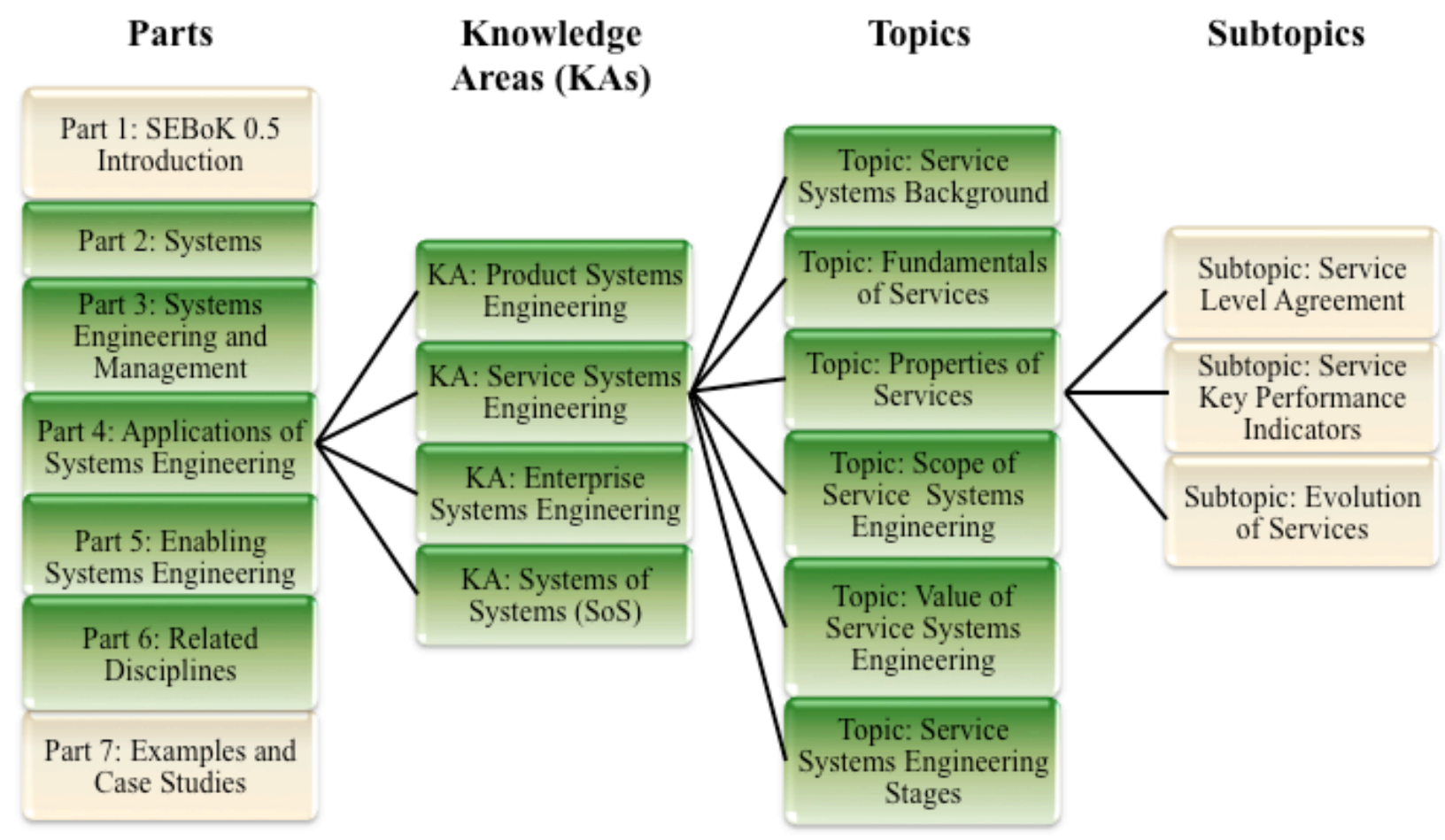

SEBoK Retained in CorBoK

Figure 2. SEBoK Structure in Relationship to the CorBoK: Example

\section{Gathering Input from BKCASE Authors}

To support the effort to define the minimum Bloom's level that all SE master's degree students should achieve by graduation in both the foundation and the concentrations, the team started by collecting inputs from a mix of twelve global BKCASE authors from industry and academia. In some cases, the respondents were familiar with the Bloom's levels and how they are used in academia; in other cases, the respondents were not familiar with Bloom's levels, which created a difference in how they assessed the Bloom's level in the survey. Each respondent provided their recommendation for whether a topic was core to the knowledge area and the expected Bloom's level of achievement at the end of the course. Although a brief set of definitions for each of the six Bloom levels in the cognitive domain were provided to the respondents and can be reviewed in Appendix A of this document, there were large differences in expectations for achievement for each topic. The collected data was analyzed for agreement that the topic was core and then for an agreement of the Bloom's level. Due to the diverse expectations of achievement as seen in the Bloom's level requirements, the mode was calculated to enable a more consistent analysis.

Figure 3 shows the percentage level of agreement between the respondents of the five SEBoK parts as it pertains to the core knowledge and the Bloom's level -see Appendix B for a brief definition of the SEBoK parts). The highest level of agreement concerning the core knowledge was within topics contained in systems part and systems engineering management part of the 
SEBoK. Additionally, Figure 3 clearly shows the lack of agreement of the Bloom's level attainment at the end of the program. Only the enabling systems engineering SEBoK part showed agreement in the Bloom's level but also had one of the lowest agreements of the required core knowledge.

\section{The Thirteenth Input}

In one case, the input was a merged set of input from a collaboration of industry representatives who also had access to the previous 12 inputs as guidance. One corporation wanted to ensure that the results of this effort strongly reflected the industry needs, as well as the perspective of academia. The BKCASE author from that corporation coordinated input from a team of systems engineering leaders to obtain a consensus input. This initial collection of the input from the individuals was done without distributing the results of the other BKCASE respondents. The people from the corporate team had previously been involved in the development of an internal SE skill set, competency model (independently validated), curriculum framework, and development/qualification program that is now in use within the corporation. They were asked to provide their input considering the SE skills and competencies that were needed to perform effective systems engineering for challenging industry applications and domains (e.g., aeronautics, computer systems, space systems, medical systems). Since the corporation had also considered Bloom's levels in determining competencies and curriculum objectives, they had a working knowledge of the levels.

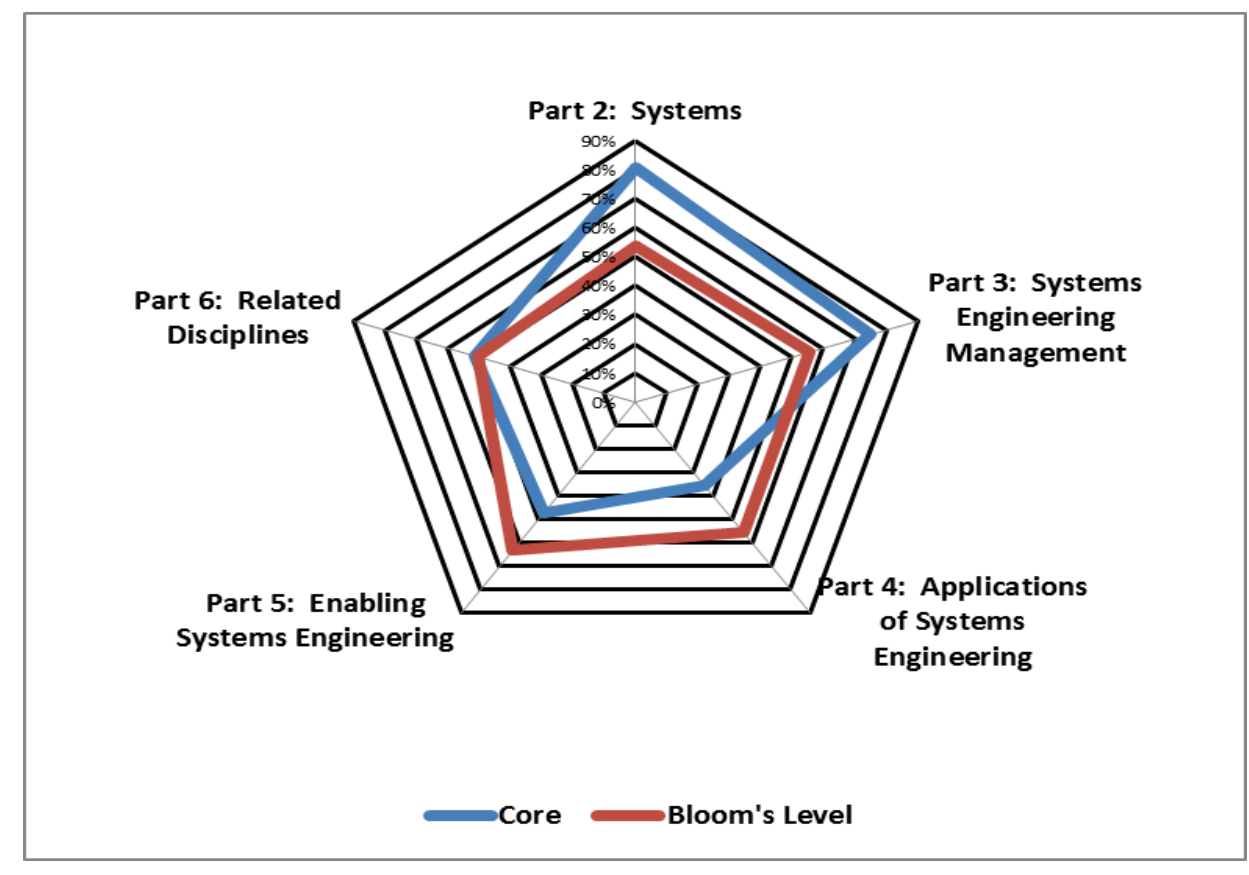

Figure 3. Core and Bloom's Level of Respondent Agreement

After the inputs were collected from the corporate team, they were consolidated and analyzed. The results were fairly consistent and any outliers were discussed to reach consensus. Next the consolidated corporate input was reviewed against the modes and averages of the previous 12 inputs to understand whether there were any significant differences. All major differences were 
noted and discussed to determine if some key factor had been overlooked in the development of the corporate consensus input. This analysis resulted in only a couple modifications, as the team felt that most differences were either justified based on the corporate skill/competency needs or that the results of the previous 12 inputs did not show enough consensus as a whole to warrant any further consideration. Finally, based on the diversity of the systems and program sizes of the corporation, the team felt that this "thirteenth" input was a fairly accurate view of the competency needs for a large part of the industry and was an essential input to include to expand the 12 individual inputs of the team members.

\section{Identifying Levels of Mastery for Foundation and Concentration Topics}

Initially, the BKCASE team interactively identified Bloom's level pairs (Knowledge/Comprehension; Application/Analysis; Synthesis/Evaluation) for the CorBoK foundation. In a follow-up effort, the team met and completed the initial assignment of Bloom's levels for each topic for both the foundation and each of the two concentrations.

In the end, every CorBoK topic was assigned a Bloom's level for the foundation topics in the CorBoK. Therefore, all 110 topics are part of the foundation. For the concentrations, if a topic was deemed to be required at a higher level of Bloom's for that concentration, a Bloom's level was assigned; if a topic was not deemed to be required at a higher level of Bloom's for that concentration, the cell was left blank. As the process was carried out, the team found that in some cases a topic belonged both in the foundation and in one or both concentrations. In the general case, the Bloom's level for the foundation was the lowest level and one or both concentrations had a higher Bloom's level. In the case where only one concentration was at a higher Bloom's level, the Bloom's level for the foundation remained unchanged. However, when both concentrations were identified at a higher Bloom's level than the foundation, a determination had to be made as to whether the foundation level still applied (in the case of new concentrations that would not require a higher level) or if the level for the foundation needed to be increased to the minimum Bloom's level of the concentrations. Of the 110 topics considered, Bloom's level were assigned by foundation and concentration (SEM and SDD) to the number of topics shown in Table 2. Where the judgment was made that the foundation should remain at the lower Bloom's level the reasoning was that we concluded that another concentration might be identified which would not demand an advanced Bloom level.

Table 2. Number of Topics Covered in Each Area

\begin{tabular}{|c|c|c|c|}
\hline Bloom's Levels & Foundation & SEM $^{*}$ & SDD $^{*}$ \\
\hline Analysis & & 11 & 8 \\
\hline Application & 15 & 6 & 22 \\
\hline Comprehension & 62 & 21 & 3 \\
\hline Knowledge & 33 & & \\
\hline Grand Total & $\mathbf{1 1 0}$ & $\mathbf{3 8}$ & $\mathbf{3 3}$ \\
\hline \multicolumn{2}{|c|}{ *SEM = systems engineering management } \\
*SDD = systems design and development
\end{tabular}

For the detailed tables summarizing the Bloom's levels for each topic for both the foundation and the concentrations, see GRCSE, version 0.5, found at http://www.bkcase.org/grcse-05/. 


\section{Defining CorBoK Touch Point Time (\%)}

The final step taken by the GRCSE team for version 0.5 was to provide guidance on the contact hours needed across a program to cover each identified topic to the level of detail necessary for the student to achieve the identified Bloom's level. Due to the differences in total contact hours from institution to institution, the GRCSE team provided these guidelines in percentages. The GRCSE team first assigned a relative distribution by part, and then using the Bloom's levels as a guide within each part, provided additional guidance down to the knowledge area level. Actual detail by topic level is left to the institution.

The first thing needed to accomplish this final step was to distribute contact time at the parts level. To this end, the GRCSE team, over a series of meetings beginning with the London 2011 BKCASE workshop, allotted the contact time distribution across the parts of the SEBoK being covered by the CorBoK. This distribution is different depending on the concentration selected (differences in \% of effort reflect differences in the minimum Bloom's levels for each concentration, combined with Bloom's levels for the foundation topics); therefore two sets of distributions were defined as shown in Table 3.

Recall that for any master's degree in SE, learning the CorBoK occupies up to half the student's time. This means that the total $(100 \%)$ time for each concentration shown in the table represents no more than half $(50 \%)$ of the time a student spends in a master's program overall. This architectural design feature enables the GRCSE recommendations to be used to delineate a baseline which all systems engineers need to know without limiting the opportunity for universities to develop programs which provide a strong development in other aspects of systems engineering, such as systems thinking, technical analysis of systems or the special needs of domains and industries outside the traditional application areas of systems engineering.

Table 3. Distribution of CorBok by "SEBoK Parts" Using Percentages" (p. 41)

\begin{tabular}{|l|l|l|}
\hline SEBoK Part & $\begin{array}{l}\text { Foundation/ } \\
\text { SEM \% }\end{array}$ & $\begin{array}{l}\text { Foundation/ } \\
\text { SDD \% }\end{array}$ \\
\hline Part 2: Systems & $12 \%$ & $12 \%$ \\
\hline Part 3: Systems Engineering and Management & $56 \%$ & $56 \%$ \\
\hline Part 4: Applications of Systems Engineering & $10 \%$ & $10 \%$ \\
\hline Part 5: Enabling Systems Engineering & $10 \%$ & $4 \%$ \\
\hline Part 6: Related Disciplines & $12 \%$ & $18 \%$ \\
\hline Total Distribution \% & $100 \%$ & $100 \%$ \\
\hline
\end{tabular}

Finally, the GRCSE team distributed the percentages allotted for each part, across the knowledge areas contained in that part, in a consistent manner based on the Bloom's level required for the majority of the topics in that knowledge area. For example, the GRCSE team had previously determined that the majority (56\%) of the contact hours for any SE graduate needed to be focused on the topics in Part 3. This percentage was consistently applied such that the most time was focused in those knowledge areas that contained sets of topics to be attained at the Analysis Bloom's level (12\%), next, at the Application level (8\%), and the lowest amount of time for those at the Comprehension level (4\%). For a 480 -hour program of which the CorBoK is $50 \%$ or 
240 hours, this roughly translates to 30 contact hours for Analysis, 20 for Application, and 10 for Comprehension. In contrast, the GRCSE team determined that just over one-tenth $(12 \%)$ of the contact hours were needed to attain the Bloom's levels provided for Part 2 (Systems). In this case the Bloom's levels to be attained were primarily at the Comprehension level and the contact hours were distributed evenly across the six knowledge areas ( $2 \%$ each). For the same 480 -hour program, this translates to about 5 contact hours for each knowledge area. The final distributions are shown in Table 4. Please note: The hours/percentages per topic are the purview of the institution with the guidance that the effort be distributed as needed to the topics within the knowledge areas to achieve the minimum Bloom's levels.

\section{Challenges and Lessons Learned}

Deciding the appropriate Bloom's level has been quite challenging and is likely to change between version 0.5 and 1.0 of GRCSE based on reviewer feedback and additional author deliberations. As we worked on the CorBoK it became clear that we were seeking a balance between extremes with respect to participants' views relative to what was expected of a graduating student. There was general consensus that familiarity with all of the topics was required, since every systems engineer needed to be able to converse about most areas of systems engineering. However, views vary about the level of comprehension a new graduate should be expected to achieve. The two extremes are:

1. That all the topics should be learned; so that whatever task is presented to the graduate an effective response can be made. This position presents the problem that to provide a brief introduction to every topic in the SEBoK demands considerable time, with the result that only a somewhat superficial knowledge could be achieved, resulting in graduates who would be able to perform only a limited range of SE tasks.

2. That topics should all be learned to the synthesis or evaluation levels of achievement so that the graduate would be ready to take responsibility for all tasks assigned. This position came from industry sources who have expressed concern about the level of preparedness of graduates.

These two positions reflect opposite poles of the breadth versus depth spectrum, neither of which, when pushed to the extreme, represents a satisfactory position. The team developing the CorBoK determined an intermediate position reflecting that all systems engineers work in a particular specialization of systems engineering, but that for different graduates that specialization will be different, and that all graduates are first assigned work in which they contribute to a project but are under the authority of more senior systems engineers who are responsible for the project as a whole. That is, it is unrealistic to expect a new graduate, even of a master's program, to be suitably equipped to take full professional responsibility for work unless they already have experience in a particular area. Rather it is reasonable to expect a new graduate working in an unfamiliar area to perform work under supervision, which would support the completion of work under the authority of an experienced systems engineer. Therefore awareness of the issues involved in many SE topics is required, and the systems engineer must be able to perform many tasks, which form part of the SE role, but does not necessarily need to be able to synthesize a set of tasks or evaluate whether the work performed is entirely suitable for the situation. These more sophisticated roles are the responsibility of the senior engineer 
responsible for the project. However, the graduate should be educated in such a way that with experience and reflection, both alone and assisted by a mentor, the graduate would be able to develop the competencies necessary to take responsibility for projects. Only after demonstrating ability and maturity would the person progress to the more senior level of contribution.

Table 4. Distribution of CorBok by "SEBoK Knowledge Areas" Using Percentages" (p. 42)

\begin{tabular}{|c|c|c|c|}
\hline Part & $\begin{array}{l}\text { Knowledge } \\
\text { Area }\end{array}$ & $\begin{array}{l}\text { Foundation/ } \\
\text { SEM \% }\end{array}$ & $\begin{array}{l}\text { Foundation/ } \\
\text { SDD } \%\end{array}$ \\
\hline \multirow{6}{*}{$\begin{array}{l}\text { Part 2: } \\
\text { Systems }\end{array}$} & Systems Overview & $2 \%$ & $2 \%$ \\
\hline & System Concepts & $2 \%$ & $2 \%$ \\
\hline & Types of Systems & $2 \%$ & $2 \%$ \\
\hline & Representing Systems with Models & $2 \%$ & $2 \%$ \\
\hline & Systems Approach & $2 \%$ & $2 \%$ \\
\hline & Systems Challenges & $2 \%$ & $2 \%$ \\
\hline \multirow{7}{*}{$\begin{array}{c}\text { Part 3: } \\
\text { Systems } \\
\text { Engineering } \\
\text { and } \\
\text { Management }\end{array}$} & Life Cycle Models & $8 \%$ & $8 \%$ \\
\hline & System Definition & $8 \%$ & $12 \%$ \\
\hline & System Realization & $8 \%$ & $12 \%$ \\
\hline & System Deployment and Use & $4 \%$ & $8 \%$ \\
\hline & Systems Engineering Management & $12 \%$ & $4 \%$ \\
\hline & Product and Service Life Management & $12 \%$ & $8 \%$ \\
\hline & Systems Engineering Standards & $4 \%$ & $4 \%$ \\
\hline \multirow{4}{*}{$\begin{array}{c}\text { Part 4: } \\
\text { Applications } \\
\text { of Systems } \\
\text { Engineering }\end{array}$} & Product Systems Engineering & $2 \%$ & $2 \%$ \\
\hline & Service Systems Engineering & $2 \%$ & $2 \%$ \\
\hline & Enterprise Systems Engineering & $4 \%$ & $2 \%$ \\
\hline & Systems of Systems (SoS) & $2 \%$ & $4 \%$ \\
\hline \multirow{4}{*}{$\begin{array}{c}\text { Part 5: } \\
\text { Enabling } \\
\text { Systems } \\
\text { Engineering }\end{array}$} & Systems Engineering Organizational Strategy & $3 \%$ & $1 \%$ \\
\hline & $\begin{array}{l}\text { Enabling Businesses and Enterprises to } \\
\text { Perform Systems Engineering }\end{array}$ & $3 \%$ & $1 \%$ \\
\hline & $\begin{array}{c}\text { Enabling Teams to Perform Systems } \\
\text { Engineering }\end{array}$ & $2 \%$ & $1 \%$ \\
\hline & $\begin{array}{c}\text { Enabling Individuals to Perform Systems } \\
\text { Engineering }\end{array}$ & $2 \%$ & $1 \%$ \\
\hline \multirow{4}{*}{$\begin{array}{c}\text { Part 6: } \\
\text { Related } \\
\text { Disciplines }\end{array}$} & Introduction & $2 \%$ & $3 \%$ \\
\hline & $\begin{array}{c}\text { Systems Engineering and Software } \\
\text { Engineering }\end{array}$ & $2 \%$ & $3 \%$ \\
\hline & Systems Engineering and Project Management & $3 \%$ & $2 \%$ \\
\hline & $\begin{array}{l}\text { Systems Engineering and Specialty } \\
\text { Engineering }\end{array}$ & $5 \%$ & $10 \%$ \\
\hline
\end{tabular}




\section{Future Plans}

The current version 0.5 of GRCSE offers a version of the CorBoK which has been considered by the team but for which critical review is desired from the community. We expect that the review will provide diverse opinions, reflecting different levels between the two pole opinions described earlier, but will also provide a richness of information, which will be a guide for refining the Bloom's levels specified. The team will respond to these review comments by revising the Bloom's levels expected. There may also be some review comments to the effect that there are additional topics that should be included. These will be considered. It is anticipated that some of these will relate to SEBoK Part 6, which relates to the connections between SE and other fields. The responses that the team will make depend in part on the changes in SEBoK Part 6. During the final year of GRCSE development there will be a strong push to get broader insight and consensus on the content of the CorBoK. In addition, the extensive review across academia and industry will help evolve a solid and validated model to serve as the GRCSE foundation.

After release of GRCSE version 1.0 it is anticipated that GRCSE will be revised periodically to ensure that it remains current. As it is applied within universities, it will continue to be refined based on lessons learned and input from stakeholders (both academic and industrial). One area of maintenance required will concern the topics and levels of achievement which are included in CorBoK and the possibility of addition of new concentration areas. Changes may arise from changes in the view of the maintainers relative to the authors or as a result of changes in systems engineering, and therefore in the education required to commence practice. The authors also expect that concentrations will be identified and developed in addition to the two examples currently included in GRCSE, System Design and Development and Systems Engineering Management.

\section{Conclusion}

In this paper we have described the context and processes used by the GRCSE team to derive the topics, structure, level of detail, Bloom's levels, and relative coverage of knowledge required for a professional graduate program in Systems Engineering. As a part of the BKCASE project the charter of GRCSE is to package the vision of Systems Engineering present in the SEBoK in a way suitable to guide university stakeholders in the creation, evaluation, and evolution of programs in Systems Engineering. The result of this international effort, GRCSE version 0.5, was made available for general review on December 15, 2011 and was available for review at http://www.bkcase.org/grcse-05/ until March 7, 2012. We believe that GRCSE 0.5 demonstrates significant progress toward the goals of the project. However, we view the current status of the document as a work in progress. The feedback received during the review period will be analyzed and incorporated into the GRCSE version 1.0 document, which is the final deliverable of the GRCSE component of the BKCASE project. We believe that this will be a major milestone in systems engineering education, but in actuality only a beginning. It is intended that this work will be delivered to INCOSE and IEEE as a foundation for future evolution of Systems Engineering curriculum at the professional masters degree level, which will continue to evolve with the needs of the society as a whole. 


\section{Acknowledgements}

The authors would like to acknowledge and thank the entire GRCSE author team for their patience with the process and the entire BKCASE author team (including GRCSE authors) for their contributions.

\section{Appendix A}

The following provided brief definitions for each of the six Bloom's levels in the cognitive domain: ${ }^{1}$ (p. 35)

- Knowledge - The ability to remember previously learned material.

- Comprehension - The ability to understand information and grasp the meaning of material presented.

- Application - The ability to use learned material in new and concrete situations.

- Analysis - The ability to decompose learned material into constituent parts in order to understand the structure of the whole. This includes seeing patterns, the organization of parts, recognition of hidden meanings, and the obvious identification of parts.

- Synthesis - The ability to put parts together to form a new whole. This involves the use of existing ideas to create new ones, generalizing from facts, relating knowledge from several areas, as well as predicting and drawing conclusions.

- Evaluation: The ability to pass judgment on the value of material within a given context or purpose. This involves making comparisons and discriminating between ideas, assessing the value of theories, making choices based on reasoned arguments, verifying the value of evidence, and recognizing subjectivity.

For further information, see GRCSE, version 0.5, found at http://www.bkcase.org/grcse-05/.

\section{Appendix B}

The SEBoK, as a guide to the literature that comprises the body of knowledge of SE, has seven parts, each covering a specific set of knowledge areas, each of which in turn contain a set of topics. There are more than 110 topics in the SEBoK; however, the CorBoK is comprised of only 110 topics, based on the topics in Parts 2 through 6 of the SEBoK. For reference we have included a complete outline of SEBoK $0.5^{1}$ (p. 34). The current version of SEBoK is available at http://www.sebokwiki.org.

\section{SEBoK 0.5 Outline}

○ Part 1: SEBoK 0.5 Introduction

O Scope of the SEBoK

- Structure of the SEBoK

○ Systems Engineering: Historic and Future Challenges

- Systems Engineering and Other Disciplines

- SEBoK Users and Uses

- Use Case 1: Practicing Systems Engineers 
- Use Case 2: Other Engineers

- Use Case 3: Customers of Systems Engineering

- Use Case 4: Faculty Members

- Use Case 5: General Managers

- SEBoK Evolution

- Acknowledgements

○ Part 2: Systems

- Knowledge Area: Systems Overview

- Topic: What is a System?

- Topic: System Context

- Topic: Overview of System Science

- Topic: Systems Thinking

- Knowledge Area: System Concepts

- Topic: Overview of System Concepts

- Topic: Complexity

- Topic: Emergence

- Knowledge Area: Types of Systems

- Topic: Classifications of Systems

- Topic: Groupings of Systems

- Topic: The Product View of Engineered Systems

- Topic: The Service View of Engineered Systems

- Topic: The Enterprise View of Engineered Systems

- Knowledge Area: Representing Systems with Models

- Topic: What is a Model?

- Topic: Why Model?

- Topic: Types of Models

- Topic: System Modeling Concepts

- Topic: Modeling Standards

○ Knowledge Area: Systems Approach

- Topic: Overview of the Systems Approach

- Topic: Exploring a Problem or Opportunity

- Topic: Systems Analysis Approach

- Topic: Synthesis of a System

- Topic: Proving a System

- Topic: Owning and Making Use of a System

- Topic: Applying the Systems Approach

○ Knowledge Area: Systems Challenges

- Topic: Complex System Challenges

- Topic: Dynamically Changing Systems

$\circ \quad$ Part 3: Systems Engineering and Management

- Knowledge Area: Life Cycle Models

- Topic: Life Cycle Characteristics

- Topic: System Life Cycle Process Drivers and Choices

- Topic: System Life Cycle Process Models: Vee

- Topic: System Life Cycle Process Models: Iterative

- Topic: Integration of Process and Product Models 
○ Knowledge Area: System Definition

- Topic: Fundamentals of System Definition

- Topic: Mission Analysis and Stakeholders Requirements

- Topic: System Requirements

- Topic: Architectural Design

- Topic: System Analysis

○ Knowledge Area: System Realization

- Topic: System Implementation

- Topic: System Integration

- Topic: System Verification and Validation

- Knowledge Area: System Deployment and Use

- Topic: System Deployment

- Topic: Operation of the System

- Topic: System Maintenance

- Topic: Logistics

$\circ$ Knowledge Area: Systems Engineering Management

- Topic: Planning

- Topic: Assessment and Control

- Topic: Risk Management

- Topic: Measurement

- Topic: Decision Management

- Topic: Configuration Management

- Topic: Information Management

- Topic: Quality Management

○ Knowledge Area: Product and Service Life Management

- Topic: Service Life Extension

- Topic: Capability Updates, Upgrades, and Modernization

- Topic: Disposal and Retirement

○ Knowledge Area: Systems Engineering Standards

- Topic: Relevant Standards

- Topic: Alignment and Comparison of the Standards

- Topic: Application of Systems Engineering Standards

○ Part 4: Applications of Systems Engineering

$\circ$ Knowledge Area: Product Systems Engineering

○ Knowledge Area: Service Systems Engineering

- Topic: Service Systems Background

- Topic:

- Topic: Properties of Services

- Topic: Scope of Service Systems Engineering

- Topic: Value of Service Systems Engineering

- Topic: Service Systems Engineering Stages

- Knowledge Area: Enterprise Fundamentals of Services Systems Engineering

- Topic: Enterprise Systems Engineering Background

- Topic: The Enterprise as a System

- Topic: Related Business Activities

- Topic: Enterprise Systems Engineering Key Concepts 
- Topic: Enterprise Systems Engineering Process Activities

- Topic: Enterprise Capability Management

○ Knowledge Area: Systems of Systems (SoS)

- Topic: Architecting Approaches for Systems of Systems

- Topic: Socio-Technical Features of Systems of Systems

- Topic: Capability Engineering

$\circ \quad$ Part 5: Enabling Systems Engineering

○ Knowledge Area: Systems Engineering Organizational Strategy

- Topic: Organizational Purpose

- Topic: Value Proposition for Systems Engineering

- Topic: Systems Engineering Governance

- Knowledge Area: Enabling Businesses and Enterprises to Perform Systems Engineering

- Topic: Deciding on Desired Systems Engineering Capabilities within Businesses and Enterprises

- Topic: Organizing Business and Enterprises to Perform Systems Engineering

- Topic: Assessing Systems Engineering Performance of Business and Enterprises

- Topic: Developing Systems Engineering Capabilities within Businesses and Enterprises

- Topic: Culture

- Knowledge Area: Enabling Teams to Perform Systems Engineering

- Topic: Determining Needed Systems Engineering Capabilities in Teams

- Topic: Organizing Teams to Perform Systems Engineering

- Topic: Assessing Systems Engineering Performance of Teams

- Topic: Developing Systems Engineering Capabilities within Teams

- Topic: Team Dynamics

- Knowledge Area: Enabling Individuals to Perform Systems Engineering

- Topic: Roles and Competencies

- Topic: Assessing Individuals

- Topic: Developing Individuals

- Topic: Ethical Behavior

- Part 6: Related Disciplines

○ Knowledge Area: Systems Engineering and Software Engineering

- Topic: The Nature of Software

- Topic: An Overview of the SWEBOK Guide

- Topic: Software Engineering and Systems Engineering: Similarities and Differences

○ Knowledge Area: Systems Engineering and Project Management

- Topic: An Overview of Project Management

- Topic: Systems Engineering and Project Management: Similarities and Differences

- Knowledge Area: Systems Engineering and Procurement/Acquisition

- Knowledge Area: Systems Engineering and Marketing/Sales

- Knowledge Area: Systems Engineering and Specialty Engineering 
- Topic: Integration of Specialty Engineering

- Topic: Reliability, Availability, and Maintainability

- Topic: Human Systems Integration

- Topic: Safety Engineering

- Topic: Security Engineering

- Topic: System Assurance

- Topic: Quality Engineering

- Topic: Electromagnetic Interference/Electromagnetic Compatability

- Topic: Resilience Engineering

- Topic: Manufacturability and Producibility

- Topic: Workplace Engineering

$\circ \quad$ Part 7: Systems Engineering Implementation Examples

- Matrix of Implementation Examples

- Case Studies

- Hubble Space Telescope Case Study

- Global Positioning System Case Study

- Medical Radiation Case Study

- FBI Virtual Case File System Case Study

- MSTI Case Study

- Next Generation Medical Infusion Pump Case Study

$\circ$ Vignettes

- Denver Airport Baggage Handling System Vignette

- Virginia Class Submarine Vignette

- UK West Coast Route Modernisation Project Vignette

- Singapore Water Management Vignette

- FAA Advanced Automation System (AAS) Vignette

- Standard Korean Light Transit System Vignette

\section{References:}

1. Pyster, A., D. Olwell, J. Anthony, S. Enck, N. Hutchison, and A. Squires, eds.; Ferris, T. lead author (2011, December 15). Graduate reference curriculum for systems engineering (GRCSE) version 0.5. Hoboken, NJ, USA: Stevens Institute of Technology. $<$ http://www.bkcase.org/grcse-05/>

2. Pyster, A., D. Olwell, A. Squires, N. Hutchison, S. Enck and J. Anthony, eds. (2011, September 19). A guide to the systems engineering body of knowledge (SEBoK) version 0.5. Hoboken, NJ, USA: Stevens Institute of Technology. $<$ http://www.sebokwiki.org $>$

3. Pyster, A. (Ed.), Graduate Software Engineering 2009 (GSwE2009): Curriculum Guidelines for Graduate Degree Programs in Software Engineering, Integrated Software \& Systems Engineering Curriculum Project, Stevens Institute of Technology, September 30, 2009. <http://www.gswe2009.org>.

4. Squires, A., (May, 2011). "Investigating the relationship between online pedagogy and student perceived learning of systems engineering competencies." Thesis, Hoboken, NJ: Stevens Institute of Technology. <see Chapter 2.1 and Appendix B http://gradworks.umi.com/34/61/3461896.html>

5. Ratcliff, J.L. (1997) What is curriculum and what should it be?, Gaff, J.G., Ratcliff, J.L., and associates, Handbook of undergraduate curriculum: a comprehensive guide to purposes, structures, practices and change, Jossey-Bass, San Francisco, pp 5-29. 